\title{
Multiflux sedimentation process of industrial suspensions without addition of a flocculant
}

\author{
Tymoteusz Turlej ${ }^{1, *}$ \\ ${ }^{1}$ AGH University of Science and Technology Cracow Sciences, Department of Power Systems and \\ Environmental Protection Facilities, Av. A. Mickiewicza 30, 30-059 Cracow, Poland
}

\begin{abstract}
The development of a closed-circular economy is an opportunity to increase its competitiveness and reduce operating costs. Repeated use of water taken from the environment in industrial plants has been used for many years. An important aspect is to maintain the required physicochemical parameters throughout the entire process. The required physicochemical parameters should be maintained by applying appropriate purification processes. The use of a closed cycle of water circulation in production processes allows reducing the load of sewage affecting the environment. Mechanical treatment of wastewater, e.g. through the use of the sedimentation process, is slow and often requires the support of coagulation or flocculation processes, and thus the use of auxiliary chemistry. At the same time, to increase the efficiency of the sedimentation process, it is possible to use multiflux fillings to accelerate the sedimentation process without the use of chemicals. The article presents the results of the use of multiflux fillings in the sedimentation process on the example of selected industrial suspensions.
\end{abstract}

\section{Introduction}

The issues of environmental protection and social responsibility of production processes more and more often refer to the idea of a circular economy [1]. This type of economy model is based on the assumption that the value of products, materials and resources is to be maintained in the economy for as long as possible to ultimately reduce waste generation to a minimum. The European Commission, in the package of proposals announced in December 2015, clearly declared that it is a priority for economic operators to use all available tools to fully implement the new ecological and raw materials policy or to develop new biofuel production techniques [2]. The Commission has proposed legislative proposals that aim to reduce food waste, develop quality standards for secondary raw materials, develop eco-design, or design that provides durability, reparability, as well as recycling or recovery [3]. The package also includes a plastics strategy regarding issues related to their recycling, biodegradation, as well as the presence of hazardous substances in plastics and a significant reduction in the amount of marine waste. The key goals of the circular economy are, among others: reaching the level of municipal waste recycling by 2030 at the level of $65 \%$, packaging waste at the level of $75 \%$, and prohibition of storing

*Corresponding author: turlej@agh.edu.pl 
selectively collected waste or support of waste recovery and recycling systems (batteries, vehicles) [3].

The idea of repeated use of water taken from the environment through its treatment in order to maintain the required physico-chemical and biological parameters has been used for many years. This particularly applies to the optimization of the work of water and wastewater systems, which cover a wide spectrum of unit processes of technological systems (e.g. hydrotransport, deironing, wastewater treatment, etc.). Sustainable management of water resources enforces the use of new treatment technologies in industrial plants and building closed water circuits, which are the basis for eco-development, industrial plants can reuse the same water, directing water used for cleaning processes and returning it to the production process [4][5]. The reuse of treated sewage requires the application of solutions ensuring the stabilization of the physical-chemical and bacteriological composition of sewage (process water) fed to the industrial installation. Water and sewage management is a particularly important aspect in the chemical industry and processing of mineral resources. In the final stages of technological processes, huge streams of suspensions are created, which should be compacted before disposal, recycling or storage occurs in order to reduce the volume of stored product (or waste), and the recycled technological water should be returned to the system. Mechanical and gravity densification is the most commonly used. The sedimentation process is beneficial from an energetic point of view, the low need for an energy is caused by necessity of aiding low flow of the suspension, as well as to subdue the resistance movement during scrapping of the sludge [6].

\subsection{Sedimentation process}

Sedimentation processes are commonly used in various fields of industry, e.g. in the chemical and food industry, processing of mineral resources or treatment of municipal sewage. Although sedimentation is beneficial for energy reasons (low energy demand in accompanying processes, e.g. pumping sludge), the low speed of the process is a decisive problem, which is why it is necessary to use various techniques to intensify this process [7]. To increase the speed of the sedimentation process, and thus the efficiency of the whole process, various types of chemical additives are used, e.g. flocculants [8] (flocculation process) or coagulants [9] (coagulation process). The use of these allows for significant improvement of the sedimentation process conditions, but is associated with additional operating costs. One of the techniques to intensify the sedimentation process without the use of chemicals is the process of so-called shallow sedimentation (multiflu sedimentation). The process of multiflux sedimentation was observed by Boycott, when he noticed that the patients' blood in inclined tubes was clarified much faster than in tubes positioned vertically [10]. The multiflux sedimentation process can be carried out in classic settling tanks by filling them with multiflux cartridges (partially or completely). Issues related to the separation of multiphase systems are so complex that new studies are continually appearing that allow a better description of the process being carried out and the results achieved [11]. The development of theories related to the description of the sedimentation process allows obtaining more detailed data on the process and exploitation of sedimentation equipment. Most often, these are studies referring to a specific application area, specific suspensions and strictly defined conditions of the sedimentation process (concentration of suspension, surface load, etc.) [12][13]. Static tests of the sedimentation process are based on the sedimentation test, i.e. plotting the sedimentation curve [14]. Determination of the position of the interface separation can be done in a classical way (registration of the separation layer by a laboratory technician) or CDD video analysis [15][16], ultrasonic methods [17] or numerical simulations [18][19]. 


\section{Research material}

Five types of suspensions, from different technological processes, were used for the research. One of the basic elements determining the sedimentation properties is density of the solid part of suspension. With the particle size and concentration of the suspension, the density of the solid phase particles determines the sedimentation velocity. Both in the design process of sedimentation devices and in the suspension sedimentation process, knowledge of the density of a part of the solid suspension is indispensable.

The suspension no. 1 came from the converter process of steel production. The suspension no. 2 was created as a result of cleaning the blast furnace gas in the scrubber. The suspension marked with number 3 is a post-flotation sludge formed in the process of copper ore enrichment. Suspension number 4 comes from a coal processing plant (enrichment). Suspension no. 5 came from the activated sludge chambers of the municipal wastewater treatment plant. The values of the determined solid phase density of each suspension are summarized in Table No. 1.

Table 1. Density of suspensions.

\begin{tabular}{|c|c|}
\hline Suspension & Density $\left[\mathbf{k g} / \mathbf{m}^{\mathbf{3}}\right]$ \\
\hline Suspension 1 & 4500 \\
\hline Suspension 2 & 3048 \\
\hline Suspension 3 & 2700 \\
\hline Suspension 4 & 2376 \\
\hline Suspension 5 & 1950 \\
\hline
\end{tabular}

\section{Static tests}

Static tests were carried out at the laboratory stand for testing the static sedimentation process, according to Norm PN-G 04570. The tests were carried out for two settings of the measuring cylinder - vertical and inclined. In the cylinder set vertically, the sedimentation process was carried out as in the device without multiflux filling, while in the inclined cylinder the sedimentation process was carried out in a settling tank with a multiflux filling. In the tests carried out, the setting of the cylinder inclined at an angle of $60^{\circ}$ relative to the ground was assumed - as a typical angle of setting the sedimentation duct in the multiflux fillings.

\subsection{Suspension 1}

For static tests of suspension 1, tests were carried out for the angle of inclination of the multiflux duct: $90^{\circ}, 75^{\circ}, 60^{\circ}$ and $45^{\circ}$. The tests were carried out for various concentrations of this suspension. The experiment started with the preparation of the suspension in the tank (mixing process). Then, depending on the sedimentation tests carried out, the concentration of the suspension was determined by diluting it with tap water. The prepared suspension was poured into the measuring cylinders at a specified height $(930 \mathrm{~mm})$. Before measurement, the contents of the cylinder were mixed again. After mixing, the cylinder was placed on the measuring stand and the measurement was conducted (reading of the position of the separation boundary between the layer of clarified water and the layer of thickened). 

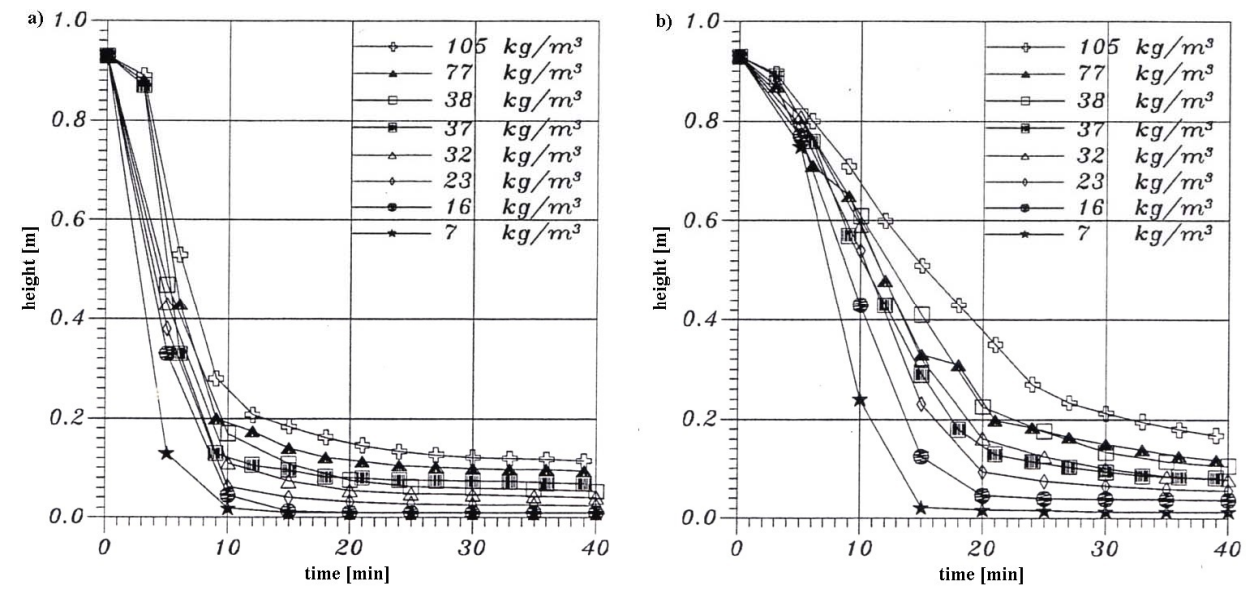

Fig. 1. Sedimentation curves for suspension 1: a) angle $45^{\circ}$, b) angle $60^{\circ}$.
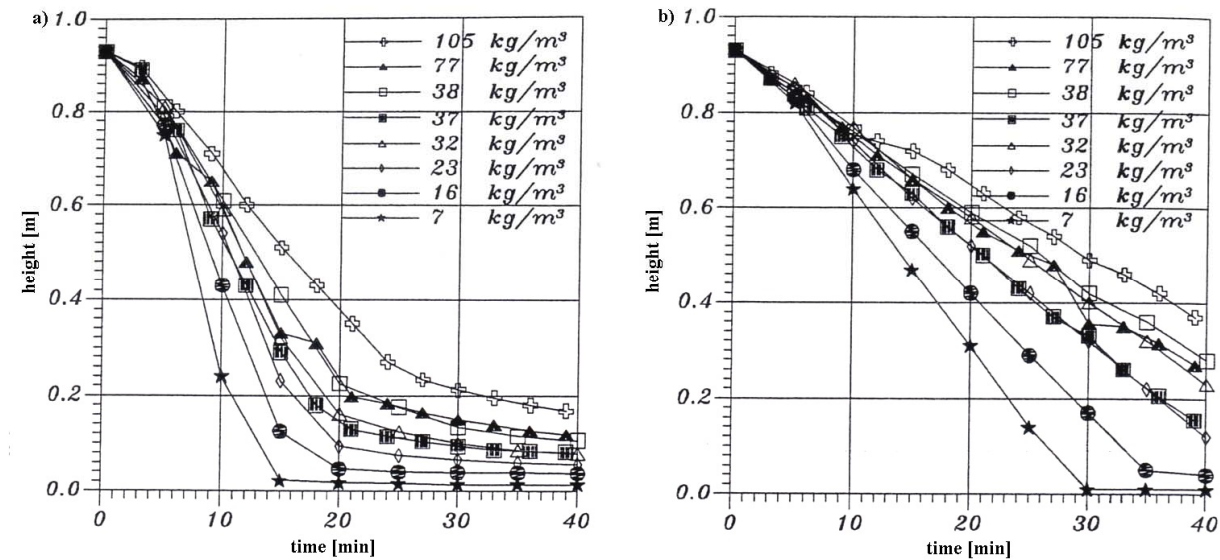

Fig. 2. Sedimentation curves for suspension 1: a) angle $75^{\circ}$, b) angle $90^{\circ}$.

\subsection{Suspension 2}
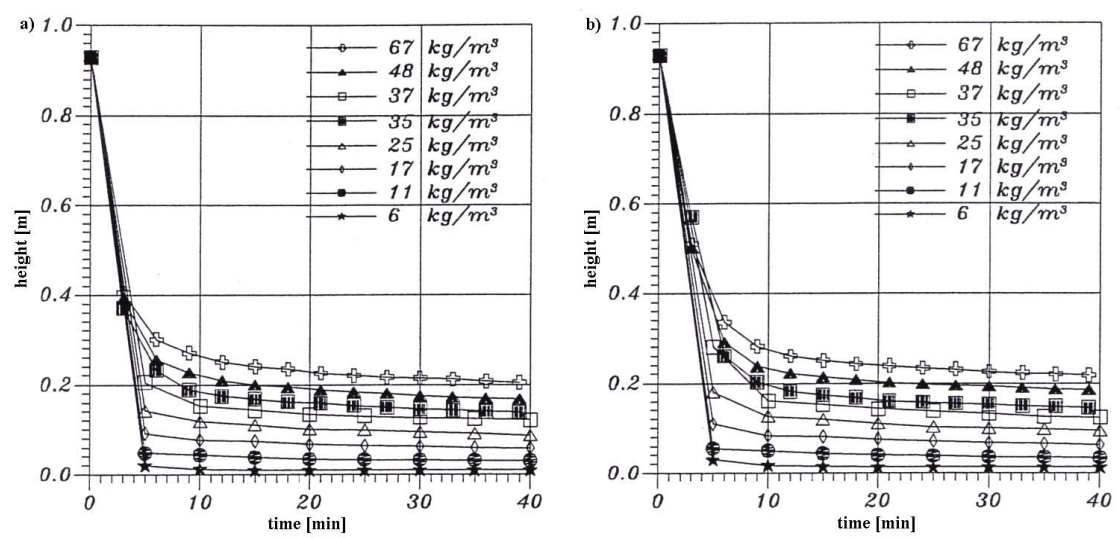

Fig. 3. Sedimentation curves for suspension 2: a) angle $45^{\circ}$, b) angle $60^{\circ}$. 

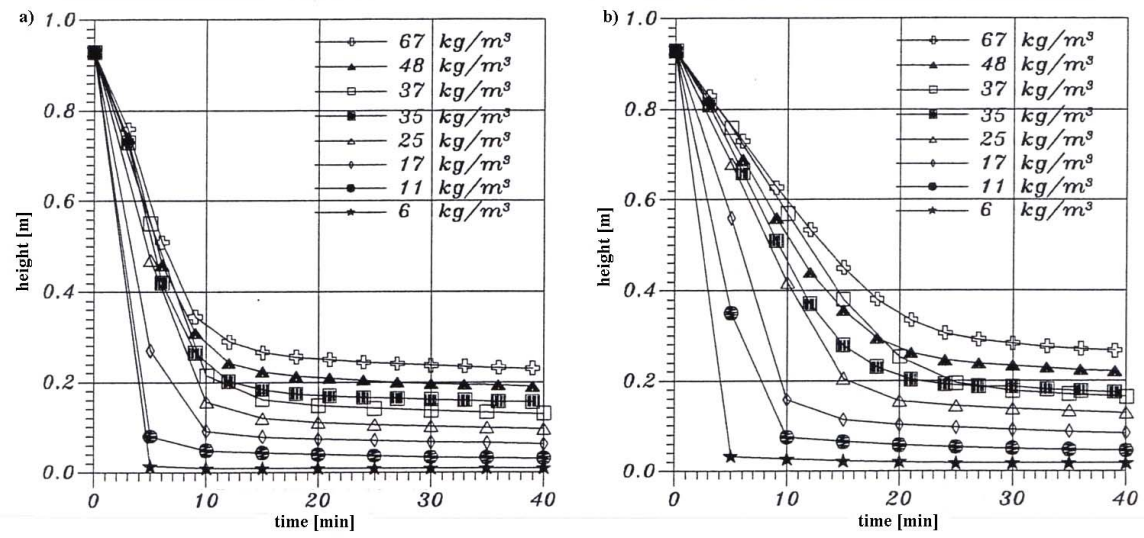

Fig. 4. Sedimentation curves for suspension 2: a) angle $75^{\circ}$, b) angle $90^{\circ}$.

For static tests of suspensions 2, tests were carried out for the angle of inclination of the multiflux duct: $90^{\circ}, 75^{\circ}, 60^{\circ}$ and $45^{\circ}$. The tests were carried out for various concentrations of these suspensions. The measurement methodology was the same as for suspension 1 .

\subsection{Suspension 3}
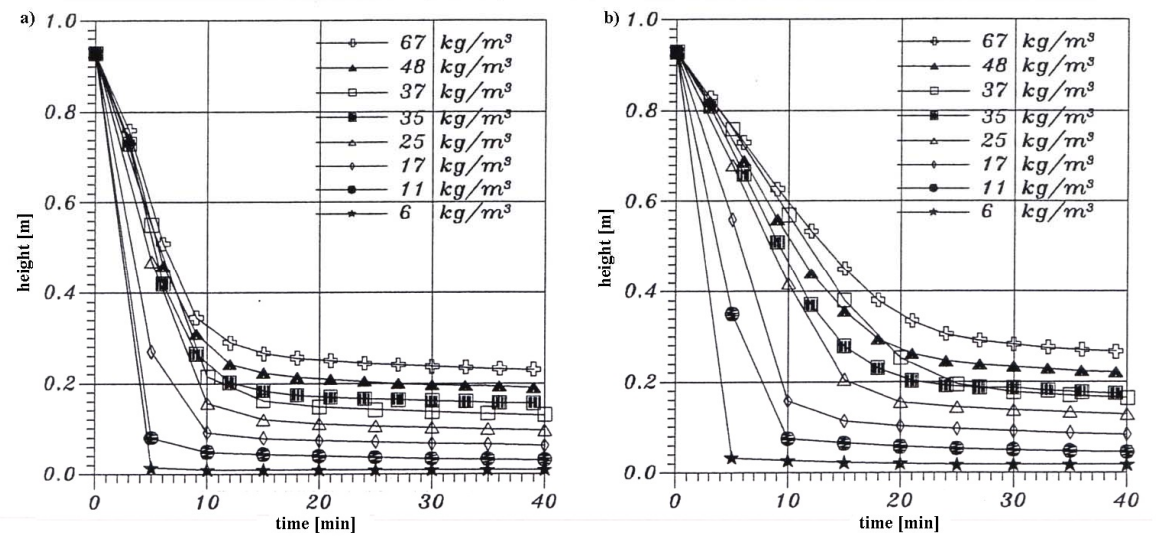

Fig. 5. Suspension 3: a) sedimentation curves, b) concentration of suspension at compression zone.

For static tests of suspension 3 , tests were carried out for the angle of inclination of the multiflux duct: $90^{\circ}, 75^{\circ}, 60^{\circ}$ and $45^{\circ}$. The tests were carried out only for one concentration of this suspension $\left(130 \mathrm{~kg} / \mathrm{m}^{3}\right)$. The measurement methodology was the same as for suspension 1. The concentration measurement was made using the filter method. The research was conducted for the two settings of the measuring cylinder - vertical and inclined.

\subsection{Suspension 4}

For static tests of suspension 4, tests were carried out for the angle of inclination of the multiflux duct: $90^{\circ}$ and $45^{\circ}$. The tests were carried out only for one concentration of this suspension $\left(45 \mathrm{~kg} / \mathrm{m}^{3}\right)$ 


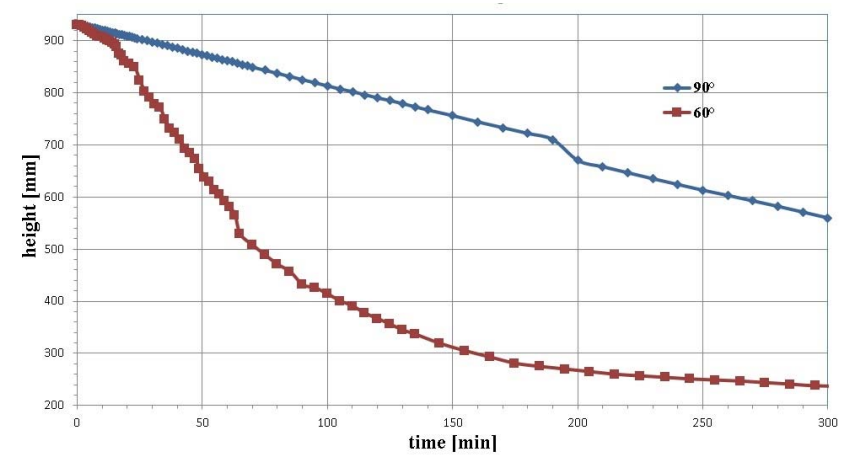

Fig. 6. Sedimentation curves for suspension 4: angle $60^{\circ}$ (multiflux sedimentation) and angle $90^{\circ}$ (classical sedimentation).

\subsection{Suspension 5}

For static tests of suspension 5, tests were carried out for the angle of inclination of the multiflux duct: $90^{\circ}$ and $60^{\circ}$. The concentration of the tested municipal suspension was not determined. The purpose of the test tests was to determine the influence of the inclination angle of a single multiflux duct on the time of sedimentation process of the municipal suspension.

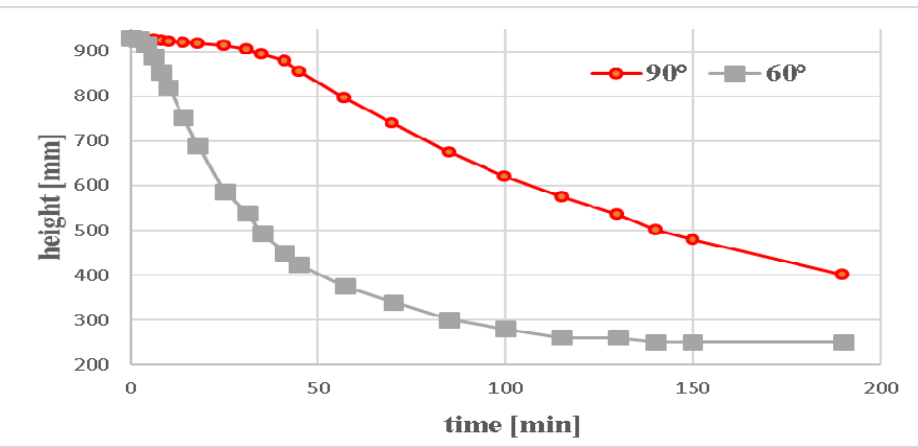

Fig. 7. Sedimentation curves for suspension 5: angle $60^{\circ}$ (multiflux sedimentation) and angle $90^{\circ}$ (classical sedimentation).

\section{Discussion}

By analyzing the graphs (Fig. $1 \div 4$ ) one can notice a certain type of irregularity. The compression zone for the suspension with the same cylinder height and lower concentration is greater than for the same conditions and higher concentration. It can be assumed that this is due to the parameters of the suspension, which had a small fraction of very large grains (large particles sediment very quickly). Their influence on the moving of the separation zone is small, but they have a big impact on the mass of the solid part in the contained sample, i.e. on the concentration of the suspension. The sedimentation tests confirm the occurrence of an increase in the sedimentation rate of diluted suspensions (suspensions of low concentrations where free sedimentation occurs) along with an increase in the angle of inclination of the measuring cylinder. At the same time, the impact on the sedimentation and thickening rate of high-concentration suspensions can be seen (constrained sedimentation and compaction [20]) (Fig. 8). The inclination of the cylinder (in which the suspension thickening process is carried out) increases the compaction speed even several times. 

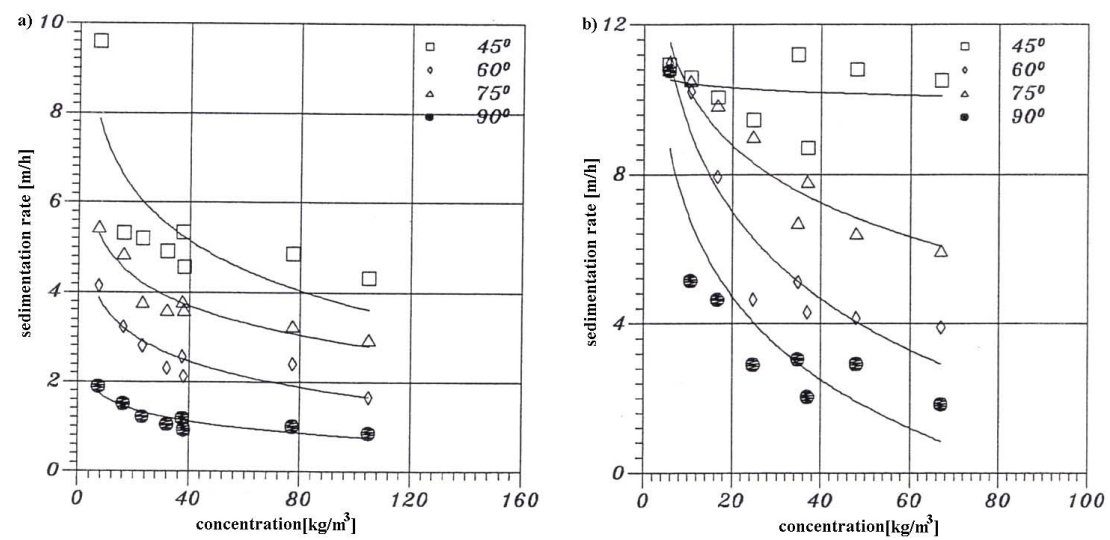

Fig. 8. Sedimentation rate: a) suspension 1, b) suspension 2 .

The charts (Fig. 8) also show that for a given suspension concentration the final level of compression is the same, regardless of the angle of inclination of the cylinder. The inclination of the cylinder does not affect the compaction of the suspension, but it affects the time at which the maximum level of compaction will be obtained. The compaction process is faster with the increasing inclination angle of the wire. The analysis of sedimentation curves shows that in the compaction process, the time at which comparatively high compaction can be achieved is of fundamental importance. This time can be shortened, among others, by increasing the area of sedimentation, e.g. by using multiflux fillings. Shortening the time at which an appropriate degree of thickening of the suspension can be achieved allows to reduce the dimensions of the device, or to increase the flow rate. Unfortunately, the density of the suspension above a certain level cannot be increased by gravitation (the so-called maximum compaction level of the suspension). The static test of the suspension 3 (from the ore enrichment process) confirmed the impact of using multiflux fillings on improving the efficiency of the sedimentation process. Similarly to suspensions 1 and 2, an increase in the rate of moving of the separation boundary for inclined cylinders is observed in relation to the situation in which compaction takes place in a vertical cylinder. For the initial suspension concentration of $130 \mathrm{~kg} / \mathrm{m}^{3}$, the average concentration in the thickened suspension layer is $150 \mathrm{~kg} / \mathrm{m}^{3}$ for the vertical cylinder and $380 \mathrm{~kg} / \mathrm{m}^{3}$ for the inclined cylinder respectively (Table 2). For a vertical cylinder, the concentration in the compression zone at level $380 \mathrm{~kg} / \mathrm{m}$ is obtained only after 390 minutes of measurement (Fig. 5). Compared to the measurement in an inclined cylinder, this time is five times longer.

Table 2. Concentration of suspension 2 (initial concentration and concentration in thickened layer).

\begin{tabular}{|c|c|}
\hline Parameter & Density $\left[\mathbf{k g} / \mathbf{m}^{\mathbf{3}}\right]$ \\
\hline Initial concentration & 130 \\
\hline Concentration in vertical cylinder & 150 \\
\hline Concentration in inclined cylinder & 380 \\
\hline
\end{tabular}

The obtained results (Fig. 6 and Fig. 7) clearly show that the sedimentation process is much faster in the system of an inclined cylinder. This dependence is true for the both suspensions: coal suspension and suspension form wastewater treatment plant. The calculated values of sedimentation rate (Tab. 3) shows that the use of multiflux fillings causes 5.2-times increase in sedimentation rate. 
Table 3. Sedimentation rate of coal suspension.

\begin{tabular}{|c|c|}
\hline Position of cylinder & Sedimentation rate $[\mathrm{mm} / \mathrm{s}]$ \\
\hline Vertical & 0,018 \\
\hline Inclined $\left(60^{\circ}\right)$ & 0,0936 \\
\hline
\end{tabular}

\section{Conclusion}

The sustainable development strategy is based on providing innovative solutions that provide millions of people around the world with a better quality of life, reducing the adverse impact of industrial plants on the natural environment, while increasing or maintaining production efficiency. One of the elements of this strategy is to limit the amount of chemicals used in industry (or the use of the so-called green chemistry). The article presents methods that intensify water and wastewater treatment processes in various branches of industry. The main goal was to demonstrate the possibility of using techniques that do not require the use of chemical additives in gravitational thickening and clarifying processes.

The conducted research confirmed the possibility of using multiflux sedimentation as an alternative to other techniques of intensifying the sedimentation process, such as coagulation or flocculation. For all suspensions tested, it is true that the sedimentation velocity is several times higher than in the case of sedimentation carried out in the classical system. This dependence is also valid for a suspension of various concentrations. The use of an increased sedimentation area allows reducing operating costs, and the ability to construct smaller settlers (maintaining the same efficiency of the process). At the same time, it should be noted that the use of flocculation or coagulation processes significantly improves the sedimentation rate (up to several times more than multiflux fillings), but is associated with additional operating costs. The selection of an appropriate method for carrying out the sedimentation process of individual suspensions should be determined individually, because the sedimentation process is influenced by many parameters (concentration, particles size distribution, chemical properties, etc.).

\section{References}

1. J. Bondaruk, J. Kwapuliński, Problemy Ekologii, 11, 5, 263-270 (2007)

2. S. Różycki, W. Kowalski, Przemysł Chemiczny, 96, 8, 1716-1718 (2017)

3. European Commission, Communication from the Commission to the Institutions, COM 614/F1 (2015)

4. Z. Nowak, (Gospodarka wodno-mułowa w zakładach przeróbki mechanicznej węgla, Wyd. Śląsk, 1982)

5. W. Blaschke, (Przeróbka węgla kamiennego - wzbogacanie grawitacyjne, Wyd. Gospodarki Surowcami Mineralnymi i Energia PAN, 2009)

6. W. Kowalski, (Osadniki wielostrumieniowe, Uczelniane Wydawnictwa naukowodydaktyczne $A G H, 2004)$

7. M. Banaś, Inżynieria chemiczna i procesowa, 25, 3, 659-664 (2004)

8. K. Kołodziejczyk, Arch. Min. Sci., 61, 1, 59-68 (2016)

9. M. Banaś, Przemysł Chemiczny, 96, 7, 1658-1661 (2017)

10. A. E. Boycott, Nature, 104, 532 (1920)

11. K. Kołodziejczyk, Przemysł Chemiczny, 96, 7, 1687-1690 (2017) 
12. M. Banaś, Przemysł Chemiczny, 96, 7, 1658-1661 (2017)

13. B. Hilger, M. Banaś, Warzecha, (SGEM 2014: 14th International multidisciplinary Scientific Geoconference, 2, 193-200, 2014)

14. G. J. Kynch, Trans. Faraday Soc., 48, 166-176 (1952)

15. T. Hubner, S. Will, A. Leipertz, Particle and Particles Systems Characterization, 18, 2, 70-78 (2001)

16. Y. Zhu, J. Shepherd, I. S. Coghill, M. Vagias, K. Elkin, Miner. Eng., 13, 7, 765-772 (2000)

17. T. N. Hunter, J. Peakall, S. R. Biggs, Miner. Eng., 24, 5, 416-423 (2011)

18. M. Banaś, Inżynieria chemiczna i procesowa, 25, 665-671 (2004)

19. K. Kołodziejczyk, Przemysł Chemiczny, 95, 8, 1488-1491 (2016)

20. Z. Orzechowski, (Przepływy dwufazowe adiabatycznie ustalone, 1990) 